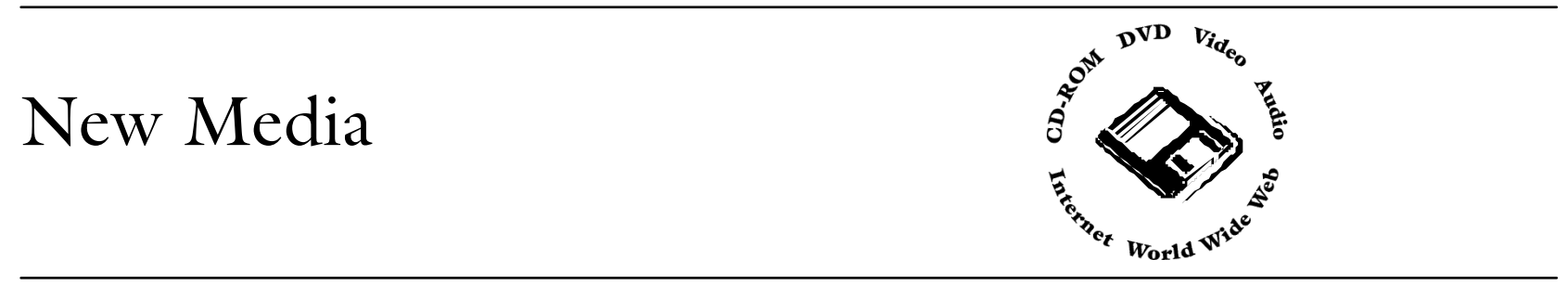

\section{Using computer technology to belp keep investigators honest}

The April 2000 issue of Anesthesia and Analgesia contains a very unusual letter to the editor (Anesth Analg 90: 1004-7). A team from Germany scrutinized 47 articles on antiemetic therapy that were published by a Japanese team. The authors of the letter used advanced statistical methods to demonstrate the existence of serious flaws in the Japanese research and conclude that "there must have been an underlying influence causing such incredibly nice data". In essence, the antiemetic data was demonstrated to be untrustworthy.

When I studied biology in university and learned about Mendel's seminal studies on the genetics of peas, the instructor in our class told us that when Mendel's published data was examined many years after his death, biostatisticians found that his data were too good to be true and suspect that he may have ignored some findings did not meet his expectations.

As investigators become more comfortable with statistical methods and as statistical software becomes less expensive and easier to use, this kind of plausibility analysis will become more frequent. Indeed, the ready availability of cheap computing may also help reduce the incidence of plagiarism. With the advent of electronic publishing it will be possible to electronically and automatically scan all electronically published reports for sequences of words that are the same or even similar. Thus, theft of sentences or paragraphs from other reports in submitted or already published manuscripts would be brought to light. Software to do this is already in development for use in detecting plagiarism among university students. In response to the increasing number of companies which sell term papers online, as well as in response to the large amount of material already available freely on the Internet, computer science researchers are developing Internet portals designed to assist university professors in detecting plagiarism. The professor, upon receiving a disk with an essay from a student, submits the file on disk to a special search engine that looks for sequences of words that exist in its database of previously published or previously submitted work. While the computational load associated with such enterprise can be enormous, one need only wait one or two generations of computers (about five years) to expect that such a service will become commonplace.

D. John Doyle MD PHD FRCPC

Toronto, Ontario

\section{Web Page Review: The Answer Page / Anesthesiology}

\section{http://theanswerpage.com/anesthesiology/}

This excellent anesthesia education site was kindly brought to my attention by Dr. Mark Glube, a senior anesthesia resident at our hospital who has used this service as a part of his preparation for the anesthesia fellowship examination. Every day, a question is posted at the site, with an accompanying answer about one to three pages in length, usually supported by extensive literature references. Most of the questions and answers are supplied by Stephen B. Corn M.D. and B. Scott Segal M.D. of the Department of Anesthesia, Harvard Medical School. If you visit the site daily you will undoubtably get a good CME experience. The exclusive sponsor of The Answer Page/Anesthesiology is Vital Signs, Inc. Plans for formal CME credits relating to this service are underway. As an example, here are the questions addressed for March 30, 2000: "Does propofol increase the chance of postoperative infection? What mechanisms may explain an association with postoperative infection?" The questions addressed on March 31, 2000 were: "Does etomidate suppress adrenocortical function? What is the mechanism of this effect? Can a single induction dose cause this effect? Do propofol, thiopental, midazolam, or methohexital share any of these effects on adrenocortical function?" The AnswerPage/Anesthesiology attempts to "follow a syllabus that mirrors the American Board of Anesthesiology Conent Outline (1996 revision), so that daily users will have completed an online review course 